\title{
Problems of Determining the Intellectual Potential of an Employee in the Digital Economy
}

\author{
Maxim Tantsyura ${ }^{1}$, Elvina Shamileva $^{1}$, Galina Olkhovaya ${ }^{1},{ }^{*}$ Anna Cherniavaia ${ }^{1}$ \\ ${ }^{1}$ Institute of Economics and Management Federal State Autonomous Educational Institution of Higher Education \\ "Crimean Federal University named after V.I. Vernadsky", Russia \\ "Email: GalinaBoyko2006@yandex.ru
}

\begin{abstract}
The article is dedicated to the problems of determining the intellectual potential of an employee in the digital economy. The authors regard the following issues: a shortage of narrow-profile scientific research, lack of consideration of the synergy of intellectual potential of employee (IPE), the one-sidedness of scientific approaches to defining the essence of IPE, weak linking of the definition of IPE to the profile of work tasks, the impossibility of an unambiguous objective assessment of individual components of IPE, the temporal nature of IPE, confusion of the concepts of intellectual potential and intellectual capital, the convergence of IPE with digital intelligence. The article contains a trial of finding the mutual source of listed above problems.
\end{abstract}

Keywords: Intellectual potential of employee, Intellectual capital, Intellectual potential of team, Synergy of intellectual potential of employees, Digital economy, Digital intellect.

\section{INTRODUCTION}

The investigation of the intellectual potential problems is interdisciplinary, versatile and multilevel in nature due to the conceptual complexity of this category and its close connection with the dynamics of socioeconomic development of society and the state.

In publications on philosophy, pedagogy, and sociology, the intellectual potential is determined through the individual's cognitive and adaptive abilities. The first includes mental properties and processes, the second - the ability to adapt the individual's qualities to the tasks' solutions and a changing situation [1]. In the economic research, the growing interest in the problem of intellectual potential was caused by the need to find new sources of competitive advantage against the background of the increasing role of knowledge and information in the system of production factors. As a result, the dominant conception defining intellectual potential from an economic point of view has become the conception of capital. Intellectual capital embodies the aggregate of knowledge and experience and comes to an asset that can generate a stream of economic benefits.
However, structurally, the intellectual potential is formed not only by knowledge and experience. S.N. Larin, A.N. Omelchenko, N.A. Sokolov believe that intellectual potential consists of social and organisational capital [2]. K.M. Rakhlin, O.Yu. Serova consider intellectual potential as "a set of opportunities in a conditional area to achieve maximum results" [3]. In another perspective, L.I. Lukicheva defines it as "...the totality of individual intellectual abilities and innovative potential of management" [4]. In many publications, intellectual capital is considered an intangible asset of an organisation, including human capital, intellectual property, structural and relational capital [5-8].

Although many authors' existence approaches to identifying intellectual potential forms, the analysis of Russian and foreign sources on the problem of research reveals a one-sided approach to the definition of the intellectual potential essence from the standpoint of capital theory. In the economic literature, the definition and structuring of intellectual potential are carried out mainly not at the level of the individual, but the level of the economic entities. The specifics that digitalisation brings to the formation, use and evaluation of intellectual potential are not sufficiently considered. 


\section{PROBLEM STATEMENT}

Thus, most of the economic research on intellectual potential is devoted to the problem of the enterprise's intellectual potential as a whole. This is because the individualisation of the approach leads to the need to include in consideration of psychological factors that cannot be the subject of economic research. Also, the organisation's intellectual potential cannot be reduced to the sum of employees' intellectual potentials, since when the potentials are combined, a synergistic effect, both positive and negative, can occur.

A negative synergistic effect of pooling potentials can arise, for example, when an intellectually more developed employee suppresses the initiative of underdeveloped employees. A positive impact is also possible, for example, when a situation of mutual motivation arises.

The risk of a negative synergistic effect of the pooling of potentials is purely economically impossible to assess; therefore, the subject of management can only consider the fact of its presence at the planning stage. And at the stage of implementing the plan, the magnitude of this risk can be assessed after the fact.

Methods to reduce the risk of negative effects can be:

1) controlled contact of employees through a moderator (real or virtual);

2) lack of communication between employees;

3 ) exclusion from the team of workers who reduce the overall intellectual potential.

Simultaneously, it should be noted that the complete or partial limitation of contacts between employees is technically problematic in a traditional enterprise and quite feasible in a virtual enterprise. Given the fact that there is an active transition to the digital economy in most of the world's economies and, as a result, virtualisation of enterprises, it is possible to predict an increase in the efficiency of the proposed methods over time.

It should also be considered that limiting employee contact can also reduce the positive synergy that could be achieved with full uncontrolled contact.

To formalise the synergy of IPE, you can use the matrix presented in table 1 .
Using the designations proposed in table 1 , the synergistic range (SR) can be determined:

$S R=S_{\max }^{+}-S_{\max }^{-}$

Considering formula (1), we can estimate the probability of positive and negative synergy:

$P\left(S^{+}\right)=\frac{S_{\max }^{+}}{S R}, P\left(S^{-}\right)=1-P\left(S^{+}\right)$

Based on formula (2), the criterion for the need to limit contacts is as follows:

$P\left(S^{+}\right)<P\left(S^{-}\right)(3)$

The influence of IPE on the intellectual potential of the team (IPT) can be expressed by the formula (4):

$\Delta S(I P E)=S(I P T)-S(I P T-I P E)$

It should also be taken into account that the synergistic effect of combining IPE depends not only on its structure but also on time (t). As employees' competencies change over time, the experience is gained, relationships between employees may vary, etc. Therefore, the IPC synergy can be represented by the formula (5):

$S_{I P T}=z\left(I P E_{1}, \ldots, I P E_{n}, t\right)$

Thus, the pooling of potentials is the "external" essence of IPE; therefore, to reveal the "internal" essence, it is necessary to consider the approaches to the definition of intellectual potential presented in table 2 .

\section{DISCUSSIONS}

Analysis of the definitions of intellectual potential, presented in table 2, allows us to conclude that they all relate to the structural approach, that is, the authors try to define the concept of "intellectual potential" by listing the elements that it includes. Summarising the opinions of the authors, the following aspects of the IPE can be distinguished:

1) qualification is a body of knowledge, abilities, skills;

2) experience - work experience in positions that involve a high intellectual workload. By intellectual workload, we mean the number of challenging and nonstandard situations at work;

Table 1. IPE Synergy Matrix $\left(\mathrm{S}_{\mathrm{IPE}}\right)$

\begin{tabular}{|c|c|c|}
\hline \multirow{2}{*}{$\begin{array}{l}\text { Status of } \\
\text { contacts }\end{array}$} & \multicolumn{2}{|c|}{ Type of synergy } \\
\hline & $\begin{array}{c}\text { Positive } \\
\text { synergy (S+) }\end{array}$ & $\begin{array}{c}\text { Negative } \\
\text { synergy (S-) }\end{array}$ \\
\hline Limited contacts & $\begin{array}{l}\text { Decreased positive synergy } \\
(-\Delta \mathrm{S}+)\end{array}$ & $\begin{array}{l}\text { Decreased negative synergy } \\
(-\Delta S-)\end{array}$ \\
\hline Unlimited contacts & $\begin{array}{l}\text { Maximum positive synergy } \\
\left(S_{\max }^{+}\right)\end{array}$ & $\begin{array}{l}\text { Maximum negative synergy } \\
\left(S_{\max }^{-}\right)\end{array}$ \\
\hline
\end{tabular}


Table 2. Approaches to the definition of intellectual potential (IP)

\begin{tabular}{|l|l|}
\hline \multicolumn{1}{|c|}{ Author } & \multicolumn{1}{c|}{ Definition } \\
\hline L.I. Lukicheva [4] & $\begin{array}{l}\text { IP is a set of personal intellectual potentials of employees, characterised by synergistic } \\
\text { links. In turn, personal intellectual potential the social of an employee is his knowledge, } \\
\text { ability to reproduce knowledge and creative ability }\end{array}$ \\
\hline $\begin{array}{l}\text { V.A. Lavrent'ev and } \\
\text { A.V. Sharina [9] }\end{array}$ & $\begin{array}{l}\text { IP is a set of theoretical knowledge, practical experience and individual methods number } \\
\text { of workers carrying out work to create innovations at industrial enterprises and } \\
\text { organisations }\end{array}$ \\
\hline $\begin{array}{l}\text { K.M. Rakhlina and } \\
\text { O.Yu. Serova [3] }\end{array}$ & $\begin{array}{l}\text { IP - a set of intellectual abilities of workers (knowledge, skills, information, values, skills, } \\
\text { etc.) and opportunities for their disclosure, development and use }\end{array}$ \\
\hline $\begin{array}{l}\text { V.A. Kojuda and } \\
\text { V.V.Volikov [10] }\end{array}$ & $\begin{array}{l}\text { IP - unites education, science, technology, all types of intellectual activity and becomes } \\
\text { the main resource in the formation of intellectual capital }\end{array}$ \\
\hline R.Ye. Yezhova [11] & $\begin{array}{l}\text { IP - knowledge, skills, high technologies, organisational culture, trademarks and other } \\
\text { elements of intellectual property }\end{array}$ \\
\hline
\end{tabular}

3) personal intellectual qualities - memory, attentiveness, creativity, ingenuity, etc.

It should also be noted that the problem of determining the IPE as a link to the work performed. Since the presence of an employee with high intellectual potential does not guarantee highly efficient execution of orders. This may be because the IPE does not correspond to the profile of the work performed, the lack of proper motivation, etc.

Another problem is the impossibility of an unambiguous objective assessment of individual components of the IPE, for example, creativity. This indicator characterising a person's intellectual qualities can be assessed only indirectly, for example, by introducing rationalisation suggestions. However, this indicator can be quite controversial, since the company cannot always implement all the employees' suggestions, no matter how creative they are.

Also, when determining the IPE, it is necessary to consider its temporary nature, which implies the presence of three components:

1) retrospective part - competencies and experience gained in the past;

2) the current part - the complexity and results of labour;

3) the promising part is the IPE forecast.

The lack of considering the time components when determining the IPE leads to a decrease in such a definition's theoretical and practical value.

The next problem in the definition of IPE is the confusion of the concepts of intellectual potential and intellectual capital [6,7]. Capital, as you know, is the value that brings added value. Thus, if the potential has a monetary value and brings income to its owner, it turns into capital. Otherwise, these two concepts cannot be identified.

Finally, one of the most pressing and debatable problems in the definition of IPE is the problem of the expediency of such a definition. In the context of the development of the digital economy and the digitalisation of the enterprise's activities, IPE's concept is losing its paramount importance. No employee can compete with a computer, not in terms of memory volume, computing capabilities, endurance, etc. In this connection, IPE's role in the production process decreases and may ultimately be reduced to zero.

At the same time, at an intermediate stage, we observe the convergence of IPE with digital intelligence, which gives rise to a new phenomenon that can be characterised as the worker's digital intelligence. This type of intelligence can be considered a set of digital competencies and abilities of an employee, allowing him to successfully digitise the work tasks that arise before him and solve them using advanced digital technologies.

\section{CONCLUSIONS}

Thus, the problems of determining the IPE in the digital economy are a shortage of narrow-profile scientific research, lack of consideration of the synergy of IPE, the one-sidedness of scientific approaches to defining the essence of IPE, weak linking of the definition of IPE to the profile of work tasks, the impossibility of an unambiguous objective assessment of individual components of IPE, the temporal nature of IPE, confusion of the concepts of intellectual potential and intellectual capital, the convergence of IPE with digital intelligence. Summarising all the above problems, we can say that all of them are somehow connected with the dialectic of the "external" and "internal" essence of the IPE, which is a philosophical problem that goes far beyond the scope of purely economic research.

\section{REFERENCES}

[1] Yu.V.Pushkarev, E.A. Pushkareva, The concept of intellectual potential development: the main dimensions and bases within the context of lifelong education (review), Novosibirsk State Pedagogical University Bulletin Vol. 7 Iss. 3 (2017) 140-156. DOI: https://doi.org/10.15293/2226-3365.1703.09 
[2] S.N. Larin, A.N. Omelchenko, N.A. Sokolov, Structure of Intellectual Potential of Enterprises: Analysis of Existing Approaches and Current Innovations, Bulletin of the Altai Academy of Economics and Law Vol. 1-1 (2020) 48-57. DOI: https://doi.org/10.17513/vaael.938

[3] K.M. Rakhlin, O.Yu. Serova, The Organization's Potential as the Basis of Its Competitiveness. Retrieved from: https://quality.eup.ru/MATERIALY9/potencial.ht $\underline{\mathrm{m}}$

[4] L.I. Lukicheva, Management of the intellectual capital of high-tech enterprises, Omega-L, 2006, $552 \mathrm{p}$.

[5] A. Kianto, P. Ritala, M. Vanhala, H. Hussinki, Reflections on the criteria for the sound measurement of intellectual capital: A knowledgebased perspective, Critical Perspectives on Accounting, Vol. 70, 2020. DOI: https://doi.org/10.1016/j.cpa.2018.05.002

[6] Ö. Çalhan, G. Akdağ, Z. Oter, Intellectual Capital, 2020. DOI: https://doi.org/10.5038/9781732127562

[7] Y.A. Nazarenko, Intellectual Capital of the Enterprise, Its Essence and Structure, Economic innovations Vol. 1(66) (2018) 128-134. DOI: https://doi.org/10.31520/ei.2018.20.1(66).128-134

[8] H. Ostrovska, Management by intellectual potential of enterprise. Galic'kij ekonomičnij visnik Vol. 55 (2019) 88-97. DOI: https://doi.org/10.33108/galicianvisnyk_tntu2018.0 2.088

[9] V.A. Lavrentyev, A.V. Sharina, Intellectual potential of the enterprise: concept, structure and directions of its development, Creative Economy Issue 3(2) (2009) 83-89.

[10] V.A. Kojuda, V.V Volikov, The intellectual potential in forming the company's intellectual capital. Retrieved from: http://www.icsti.su/uploaded/201003/intel_prop/5. pdf

[11] R.Ye. Ezhova, Factors and conditions for improving intellectual potential management's efficiency, Bulletin of the Moscow state open University Issue 2(39) (2010) 80-84. 